\title{
BMJ Open Association between occupational health and safety knowledge and behaviours among migrant workers: results from a cross-sectional study in China
}

\author{
Ruwei Hu (D) , ${ }^{1}$ Nan Hu, ${ }^{2,3,4}$ Ruqing Liu, ${ }^{5}$ Leiyu Shi, ${ }^{6}$ Jingrong Shi, ${ }^{7}$ Li Ling (D) 8
}

To cite: Hu R, Hu N, Liu R, et al. Association between occupational health and safety knowledge and behaviours among migrant workers: results from a cross-sectional study in China. BMJ Open 2020;10:e040143. doi:10.1136/ bmjopen-2020-040143

- Prepublication history and additional material for this paper is available online. To view these files, please visit the journal online (http://dx.doi.org/10. 1136/bmjopen-2020-040143)

$\mathrm{RH}, \mathrm{NH}$ and RL contributed equally.

$\mathrm{RH}, \mathrm{NH}$ and $\mathrm{RL}$ are joint first authors.

Received 06 May 2020 Revised 22 0ctober 2020 Accepted 26 October 2020

Check for updates

(C) Author(s) (or their employer(s)) 2020. Re-use permitted under CC BY-NC. No commercial re-use. See rights and permissions. Published by BMJ.

For numbered affiliations see end of article.

Correspondence to

Dr Li Ling;

lingli@mail.sysu.edu.cn

\section{ABSTRACT}

Objectives To assess the relationship between occupational health and safety $(\mathrm{OH} \& \mathrm{~S})$-related behaviours of migrating workers in China and their knowledge regarding $\mathrm{OH} \& \mathrm{~S}$ laws and regulations (L\&Rs).

Materials and methods We sampled 1282 migrant workers from 12 labour-intensive manufacturers in Guangdong, China, with a response rate of $98.6 \%$. Self-reported questionnaires were completed by the participants. Logistic regression models were used to examine the association between $\mathrm{OH} \& \mathrm{~S}$-related behaviours and knowledge among migrant workers adjusting for their demographic features and the survey sites.

Results Migrant workers' behaviour of seeking occupational disease (OD) diagnosis and treatment was found to be statistically significantly correlated with their knowledge of all three OH\&S L\&Rs. A higher score of knowledge regarding these $\mathrm{OH} \& S$ L\&Rs is associated with a better chance to seek OD diagnosis and treatment. The ORs of the high-score group (subjects correctly answered more than one question) versus the low-score group (subjects correctly answered less than or equal to one question) are 2.02 (95\% Cl: 1.33 to 3.07$)$ for Law of Occupational Disease Prevention and Treatment, 2.89 (95\% Cl: 1.65 to 5.09) for Regulations on Safe Management of Dangerous Chemicals and Regulations on Labor Protection for Using Toxic Substances in Workplace and 2.25 (95\% Cl: 1.34 to 3.77) for Work-Related Injury Insurance Regulations. However, knowledge about these L\&Rs is not statistically significantly associated with $\mathrm{OH} \& \mathrm{~S}$-related protective behaviours such as wearing a mask or gloves at work.

Conclusions Knowledge of OH\&S L\&Rs helps migrant workers in China to seek OD diagnosis and treatment.

\section{INTRODUCTION}

The association between knowledge and behaviour is well known. For example, some researchers have found a significant relationship between advanced mathematical knowledge and problem-solving behaviour among college students. ${ }^{1}$ Schwartz has found that knowledge may exert indirect effects on behaviour by influencing attitudes, ${ }^{2}$ whereas Douglas and Douglas have

\section{Strengths and limitations of this study}

- This cross-sectional study could not examine the causal effect of knowledge of occupational health and safety laws and regulations on occupational health behaviours.

- The workers and the factories were sampled from only one province, and the subjects might not be well representative of Chinese workers.

- The occupational health behaviours on the questionnaire were self-reported and could therefore be inaccurate.

- We did not create a job exposure matrix to assess exposures to toxic chemicals. In a further study, we should add this procedure to assess occupational safety quantitatively.

- Data could be used inappropriately despite our clear statement of confidentiality.

suggested that knowledge is not an entirely independent factor that can determine behaviour. ${ }^{3}$ Similarly, there exists evidence that legal knowledge is associated with individuals' behaviours. For example, knowledge of criminal law could help prevent committing a crime ${ }^{45}$; familiarity of traffic law may help prevent a knowing traffic violation $^{6}$; knowing food safety regulations may guide one's dietary habit ${ }^{7}$; and knowing the tobacco control laws and regulations (L\&Rs) may intervene people's smoking behaviour in public. $^{8}$

It is also reported that knowledge of occupational health and safety (OH\&S) L\&Rs is associated with $\mathrm{OH} \& \mathrm{~S}$ behaviours under some circumstances. ${ }^{9}$ For example, taxi drivers' and clients' knowledge of tobacco-related L\&Rs is a key element of successfully implementing legislations for smoke-free taxis. ${ }^{10}$ Some previous studies have reported a positive relationship between OH\&S knowledge and attitudes towards occupational behaviours. ${ }^{11-13}$ However, we believe that we not only need to consider whether knowledge is related to 
workers' attitudes but also whether knowledge ultimately leads to certain behaviours that may promote workers' health and safety awareness. According to the theory of planned behavior (TPB), behavioural decisions are not made spontaneously, but are the results of a reasoned process in which behaviour is influenced by attitudes, norms and perceptions of control over the behaviour indirectly and is influenced by intention directly. ${ }^{14}$ Based on the TPB theory, we posited that knowledge is a precursory variable to creation of certain behaviours. Therefore, we hypothesised that OH\&S L\&R-related knowledge would have a positive effect on occupational health behaviours. Specifically, workers with a positive attitude towards OH\&S L\&Rs would, in general, pay more attention to the knowledge of them and would act to implement certain health protection measures by themselves.

Some studies have been conducted to examine relationships between satisfaction of $\mathrm{OH} \& \mathrm{~S}$ policy and voting behaviour and between smoking-related policy and attitude. ${ }^{15}$ However, to date, there have been no studies reporting the association between knowledge of OH\&S L\&Rs and behaviours among frontline workers, especially for migrating workers within labour-intensive manufacturers in China. These studies are especially important for medium-small enterprises (MSEs) in China because they are a major part of China's labour forces and are facing significant challenges in OH\&S. Most of the migrant workers in China have very low education levels in general and lack proper legal knowledge and relevant training regarding occupation-related disease prevention and safety measures; hence, their health and safety awareness is usually low. ${ }^{16-18}$ The purpose of this study was to examine the relationship between knowledge of occupational health laws and related behaviours among workers in MSEs in Southern China and to compare legal knowledge, health practice and their relationship between migrant workers and resident workers. Using the questionnaire-based in-person survey on more than 1200 migrant workers from 37 labour-intensive factories in Guangdong province, we investigated which $\mathrm{OH} \& \mathrm{~S}$ behaviours could be associated with the legal knowledge of OH\&S L\&Rs among migrating frontline workers in labour-intensive factories. Our study is a survey-based study in this field in China and could help provide valuable evidence for policymakers to promote occupational health in China.

\section{METHODS AND MATERIALS \\ Sampling}

We performed a power calculation before the sampling procedure, and it indicated that a total of 1000 effective samples were needed. We estimated that about $20 \%$ of samples we would collect may not be valid for our study. Thus, we decided to sample $1250+$ migrating workers from MSEs in the cities of Guangzhou, Foshan, Zhaoqing, Qingyuan and Shaoguan. Based on the proportion of migrant workers in these cities ${ }^{19}$ we determined the number of samples within each of the cities listed above. For each city, we randomly sampled several MSEs. At least 30 subjects were collected from day-shift migrant workers on the sampling day. One participant aged $\geq 16$ years with $\geq 3$ months of residency at the current district and $\geq 1$ month of work at the current MSE without audiovisual impairment, mental illness or other difficulties in cooperation was recruited. In total, 1300 participants were invited to fill in the questionnaire, and 1282 returned the questionnaire with a response rate of $98.6 \%$. Of the 1282 study participants, 708 were men and 574 were women.

\section{Patient and public involvement}

No patient was involved.

\section{Survey}

We then conducted a cross-sectional survey for all the eligible participants, including both migrant and local workers. Qualitative study, including in-depth interview, focus group discussion and documentary analysis, was also performed. A wide range of toxic chemicals, including isocyanides, asphyxiating gases, benzene and trinitrotoluene, were in heavy use in China. But inadequate personal protective equipment (such as gloves and respirators) was in use, and no risk communication training was conducted in exposed workers. ${ }^{20}$ Exposure to toxic chemicals leading to occupational poisoning has been a long-standing problem in Chinese industry. Chemical poisoning continues to be a serious problem. Official statistics indicated that the incidence of acute and chronic chemical poisoning was 38412 cases during 1991-2006. ${ }^{21}$ Despite the existence of occupational L\&Rs in China, little progress has been made. Workers in the manufacturing industry are exposed to a variety of toxic chemicals that are present in adhesives, glues and solvents, such as benzene, toluene, xylene, methyl ethyl ketone, acetone, n-hexane, gasoline and other organic solvents, of which a high concentration of benzene has been of particular health concern. General conditions in these workplaces were described as having no or inadequate ventilation and little or no personal protection..$^{22}$ Although high concentrations of benzene were also found in large enterprise workplaces, the situation was generally worse in MSE workplaces, where more benzene poisoning cases were identified. So, we selected the MSEs of manufacturing industry in Guangdong province. The detailed survey questions and response rate can be found in online supplemental document and table S1.

\section{Statistical analysis}

The demographic features of student participants were summarised as $\mathrm{N}(\%)$ for categorical variables and mean (SD) for continuously measured variables. Univariable and multivariable logistic regressions ${ }^{23}$ were used to relate the legal knowledge scores to the corresponding occupational health behaviours. In the multivariable analysis, potential confounding variables were adjusted for. These variables include the survey participants' age, gender, marital status, education, migration status, 'Hukou' 
Table 1 Individual demographic, migration, and work characteristics and OH\&S behaviours

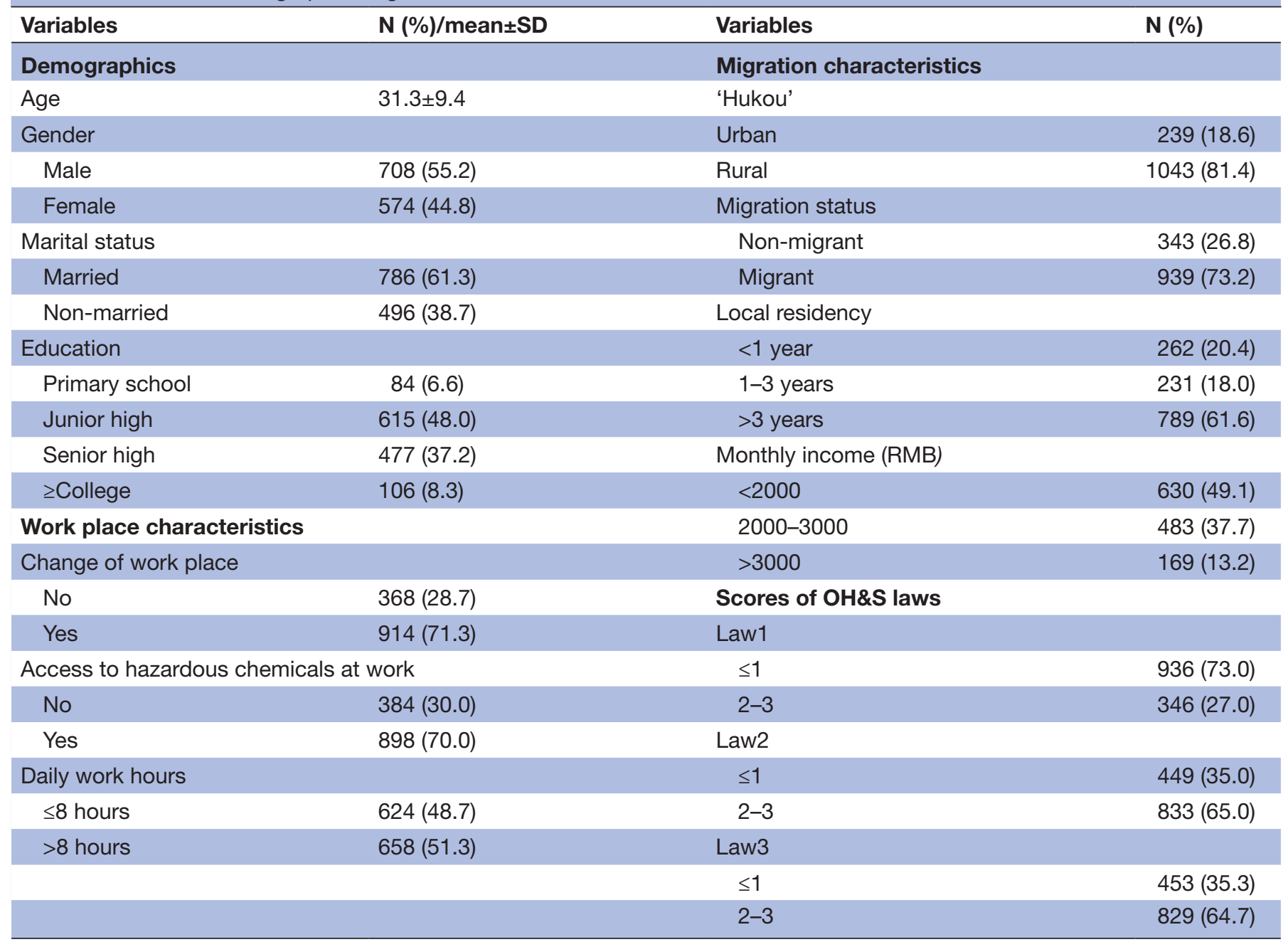

OH\&S, occupational health and safety.

status (whether the original residency is urban or rural), time as a local resident, whether the survey participants have changed their work, their working hours per week, whether they are exposed to toxic chemicals during work and the factory of the survey participants. All analyses were performed using statistical software R (www. r-project.org) and Stata (Stata, College Station, Texas, USA). In all hypothesis tests, $p$ values less than 0.05 were considered statistically significant.

\section{RESULTS}

\section{Characteristics of the survey participants}

The characteristics of the participants are given in table 1 . In brief, the age of survey participants was between 16 and 59 years, with an average age of 31.3 years. Men account for more than half of the study cohort. Among these subjects, more than $60 \%$ were married, more than $80 \%$ were from rural areas and $92 \%$ had an education level lower than or equal to senior high school graduates. About half of the study participants had a monthly income less than 2000 RMB. Most of the study participants had changed their work before the survey. A slightly more than half of these subjects worked more than 8 hours per day, and $70 \%$ of them knew that they accessed hazardous/toxic chemicals at work. At the time of the survey interview, more than $60 \%$ of the workers were local residents for more than 3 years.

\section{Association between legal knowledge and occupational health behaviour}

Table 2 reports ORs and their $95 \%$ CIs for the association between each of the three behaviours and each of the three legal knowledge scores from multivariable logistic models. All ORs reported in table 2 were adjusted for age, gender, marital status, education, migration status, 'Hukou' status, time as a local resident, whether the worker has changed his/her work, working hours, whether the worker was exposed to toxic chemicals during work and the survey factory. The chance to seek occupational disease diagnosis or treatment is statistically significantly associated with all legal knowledge scores $(p=0.001,0.001$ and 0.002 for knowledge of Law1, Law2 and Law3, respectively). The odds to seek occupational disease diagnosis/ 
Table 2 ORs $^{*}$ and their $95 \%$ Cls for the association between each of the three behaviours and each of the three legal knowledge scores from multivariable logistic models

\begin{tabular}{llll}
\hline & Seeking OD dx/Trt & Wearing mask at work & Wearing gloves at work \\
\hline $\begin{array}{l}\text { Law1† } \\
\text { Unadjusted }\end{array}$ & $3.19(2.19$ to 4.65$)$ & $1.29(1.01$ to 1.66$)$ & $1.47(1.12$ to 1.92$)$ \\
\hline $\begin{array}{l}\text { Adjusted } \\
\text { Law2 } \ddagger\end{array}$ & $2.02(1.33$ to 3.07$)$ & $0.88(0.65$ to 1.20$)$ & $1.02(0.75$ to 1.39$)$ \\
\hline Unadjusted & $3.81(2.25$ to 6.43$)$ & $1.59(1.25$ to 2.02$)$ & $1.57(1.23$ to 1.99$)$ \\
\hline Adjusted & $2.89(1.65$ to 5.09$)$ & $1.20(0.90$ to 1.60$)$ & $1.07(0.85$ to 0.93$)$ \\
\hline Law3§ & & & $1.63(1.28$ to 2.07$)$ \\
\hline $\begin{array}{l}\text { Unadjusted } \\
\text { Adjusted }\end{array}$ & $2.87(1.77$ to 4.66$)$ & $1.27(1.00$ to 1.61$)$ & $1.24(0.93$ to 1.64$)$ \\
\hline
\end{tabular}

${ }^{*}$ ORs from univariable (unadjusted) and multivariable (adjusted) logistic model adjusted for age, gender, marital status, education, migration status, 'Hukou' status, time as a local resident, whether the worker has changed his/her work, working hours, whether the worker was exposed to toxic chemicals during work and the survey factory.

†Law1 = Law of Occupational Disease Prevention and Treatment.

‡Law2= Regulations on Safe Management of Dangerous Chemicals and Regulations on Labor Protection for Using Toxic Substances in Workplace.

$\S$ Law3= Work-Related Injury Insurance Regulations.

$\mathrm{dx} / \mathrm{Trt}$, diagnosis and treatment; $\mathrm{OD}$, occupational disease.

treatment among workers who gained a higher score of Law1 knowledge is twice the odds for workers with a lower score for the same legal knowledge ( $\mathrm{OR}=2.02,95 \%$ CI: 1.33 to 3.07$)$. Similarly, the odds among workers who are more knowledgeable on Law2 and Law3 more than doubled (for Law2, OR=2.89, 95\% CI: 1.65 to 5.09; for Law3, OR=2.25, 95\% CI: 1.34 to 3.77) when compared with the counterparts with lower scores for the same legal knowledge. The other two OH\&S behaviours, wearing mask at work and wearing protective gloves at work, are not significantly associated with the knowledge of three L\&Rs (Law1, Law2 and Law3) when all of the aforementioned covariates are adjusted for.

\section{DISCUSSION}

Unsafe working conditions and occupational diseases have been widely reported in the Chinese and foreign media. ${ }^{24} 25$ According to 2003 statistics, about $80 \%$ of deaths in mining and construction sectors and in occupations involving exposure to dangerous chemicals occurred to migrant workers. Migrant workers in China, moreover, have low health risk awareness ${ }^{2627}$ and low rates of both injury insurance coverage $(23.6 \%)$ and medical insurance participation (16.7\%) (China National Bureau of Statistics 2011), making them a group of vulnerable population.

To the best of our knowledge, so far, there are no previous studies that examined the relationship between knowledge of OH\&S L\&Rs and behaviours of seeking OD diagnosis and treatment as well as wearing mask/gloves at work. This is the major motivation of our study. In this work, we found that workers with better knowledge of OH\&S L\&Rs are more likely to seek OD-related diagnoses and treatments. However, the OH\&S L\&R knowledge is not positively associated with occupational health protective behaviours such as wearing protective mask or gloves at work. We think that these protective behaviours would depend on workers' own attitude towards their safety and the safety management system enforced by the mangers or safety climate in the factories. ${ }^{28}{ }^{29}$ According to the research by Xiao and colleagues, ${ }^{30}$ occupational safety behaviours can be divided into work postures, operational safety, personal protections and health habits. Wearing mask and gloves at work is more likely to be a personal protection, which has relationship with the attitude of workers on the safety management of the factories.

Migrant workers face multiple obstacles that work against their abilities to protect themselves from workplace hazards. Generally speaking, these workers have low level of education and lack experience with industrial settings. A result from these facts is their low level of understanding of health behaviours and the rights provided by OH\&S L\&Rs. Most migrant workers, including those in MSEs, often work with a short-term contract or even without contract. Many of them may not have been employed long enough to develop certain kinds of occupational diseases, such as pneumoconiosis or chronic chemical poisoning. These diseases, however, can appear later on after the workers have returned to their hometowns, making it impossible for them to claim for compensation and medical treatment. ${ }^{22}$ This study suggests that there is an urgent need for OH\&S L\&R education programmes as well as operation education in China. Courses and programmes on personal legal protection of occupational health are strongly recommended and should be built formally into the workers' education and management 
in MSEs. Policymakers and managers must recognise the significant role that workers' human rights protection (especially when and where they go to seek OD diagnosis and treatment) plays in teaching and reinforcing safety attitudes and behaviour to migrant workers before and after developing occupational diseases.

\section{Study strengths and limitations}

Our results provided evidence in support that knowledge of OH\&S L\&Rs helps migrant workers in China to seek OD diagnosis and treatment. To our knowledge, this is the first report on the association between knowledge of OH\&S L\&Rs and behaviours of seeking OD diagnosis and treatment globally.

This study also has some limitations. First, this crosssectional study could not examine the causal effect of knowledge of OH\&S L\&Rs and occupational health behaviours. Second, the workers and the factories were sampled from only one province, and the subjects might not be a representative sample of Chinese workers, so our findings cannot be generalised before they are replicated in other Chinese provinces. Moreover, the use of self-reported questionnaire might introduce inaccurate records on occupational health behaviours. Misreporting of OH\&S-related behaviours was likely to occur, due to social undesirability of migrant workers' occupational health concerns about the inappropriate use of data despite our clear statement of confidentiality before survey. Finally, we did not create a job exposure matrix to assess exposures to toxic chemicals. In a further study, we should add this procedure of assessing occupational safety quantitatively.

\section{CONCLUSIONS}

To conclude, we found that knowledge of OH\&S L\&Rs among Chinese migrant workers is statistically significantly associated with their health behaviour of seeking OD diagnosis and treatment. Hence, training to enhance $\mathrm{OH} \& \mathrm{~S}$ knowledge may promote these migrant workers to seek OD diagnosis and treatment. We did not find statistically significant associations between OH\&S knowledge and safety behaviours, such as wearing protective gloves and masks at work, among these migrant workers. It is believed that only wearing gloves and a mask will protect them from health and safety hazards. Since health and safety awareness among frontline workers is low, we suggest health policymakers in China to legislate in order to urge and encourage MSE employers of the labourintensive industry to give their frontline workers compulsory safety training before the workers start their work or rotate to a new position.

\footnotetext{
Author affiliations

${ }^{1}$ Department of health management and policy, School of Public Health, Sun Yat-sen University, Guangzhou, Guangdong, China

${ }^{2}$ Florida International University, Miami, Florida, USA

${ }^{3}$ Department of Family and Preventive Medicine, University of Utah School of

Medicine, Saltlake City, United States
}

${ }^{4}$ Robert Stempel College of Public Health and Social Work, Miami, United States ${ }^{5}$ Guangdong Provincial Engineering Technology Research Center of Environmental Pollution and Health Risk Assessment, Department of Occupational and

Environmental Health, School of Public Health, Sun Yat-sen University, Guangzhou, China

${ }^{6}$ Johns Hopkins University, Baltimore, Maryland, USA

${ }^{7}$ Department of Data Mining and Analysis, Guangzhou Tianpeng Technology Co., Ltd, Guangzhou, China

${ }^{8}$ Department of Medical Statistics, School of Public Health, Sun Yat-sen University, Guangzhou, Guangdong, China

Acknowledgements We thank Jiajie Liang, BS for his effort on the literature search and review.

Contributors RH designed the study, participated in the workers' survey and drafted the manuscript. NH and RL oversaw the study design, participated in the data analyses and drafted the manuscript. JS participated in the the workers' survey and data analyses. RL participated in the workers' survey. LS oversaw the study design and edited the language of this manuscript. LL participated in the design of the study and was in charge of the database. All authors read and approved the final manuscript.

Funding This work was supported by the Chinese Medicine Board in New York (the grant number: CMB No. 09-984 and CMB No.15-224). We would like to sincerely thank the participating factories and workers for their fruitful cooperation. RH's research was partially supported by the Soft Science Project of Guangdong Science and Technology Plan (No. 2017A070706007). NH's research was partially supported by the University of Utah Study Design and Biostatistics Center, with funding in part from the Public Health Services research grant numbers. UL1-RR025764 and C06-RR11234 from the National Center for Research Resources. The study was sponsored by China Medical Board, Construction project of Sun Yat-sen Center for Migrant Health Policy (grant number 09984).

Disclaimer The funder had no further role in the study design, data collection, analyses or interpretation of the data, writing of the report or the decision to submit the paper for publication.

Competing interests Author Jingrong Shi was employed by the company Guangzhou Tianpeng Technology Co.,Ltd. The remaining authors declare that the research was conducted in the absence of any commercial or financial relationships that could be construed as a potential conflict of interest.

Patient consent for publication Not required.

Ethics approval This survey was approved by the Ethics Committee of Sun YatSen University (approval number 201327). This research was conducted according to the World Medical Association Declaration of Helsinki-Ethical Principles for Medical Research Involving Human Subjects.

Provenance and peer review Not commissioned; externally peer reviewed.

Data availability statement No data are available.

Supplemental material This content has been supplied by the author(s). It has not been vetted by BMJ Publishing Group Limited (BMJ) and may not have been peer-reviewed. Any opinions or recommendations discussed are solely those of the author(s) and are not endorsed by BMJ. BMJ disclaims all liability and responsibility arising from any reliance placed on the content. Where the content includes any translated material, BMJ does not warrant the accuracy and reliability of the translations (including but not limited to local regulations, clinical guidelines, terminology, drug names and drug dosages), and is not responsible for any error and/or omissions arising from translation and adaptation or otherwise.

Open access This is an open access article distributed in accordance with the Creative Commons Attribution Non Commercial (CC BY-NC 4.0) license, which permits others to distribute, remix, adapt, build upon this work non-commercially, and license their derivative works on different terms, provided the original work is properly cited, appropriate credit is given, any changes made indicated, and the use is non-commercial. See: http://creativecommons.org/licenses/by-nc/4.0/.

\section{ORCID iDs}

Ruwei Hu http://orcid.org/0000-0002-4651-3456

Li Ling http://orcid.org/0000-0003-3292-274X 


\section{REFERENCES}

1 Koichu B. On the relationships between (relatively) advanced mathematical knowledge and (relatively) advanced problem-solving behaviours. Int J Math Educ Sci Technol 2010;41:257-75.

2 Schwartz NE. Nutritional knowledge, attitudes, and practices of high school graduates. J Am Diet Assoc 1975;66:28-31.

3 Douglas PD, Douglas JG. Nutrition knowledge and food practices of high school athletes. J Am Diet Assoc 1984;84:1198-202.

4 Andrew VP, Traceyl M, Jeffrey F. Criminology: why do criminals obey the law? The influence of legitimacy and social networks on active gun offenders. J Criminal Law 2012;102:397-440.

5 Larkin JR, Paul J. Public choice theory and over criminalization. Harvard J Law Public Pol 2013;36:715-93.

6 Strine TW, Beck L, Bolen J, et al. Potential Moderating role of seat belt law on the relationship between seat belt use and adverse health behavior. Am J Health Behav 2012;36:44-55.

7 Kristal AR, Bowen DJ, Curry SJ, et al. Nutrition knowledge, attitudes and perceived norms as correlates of selecting low-fat diets. Health Educ Res 1990;5:467-77.

8 Pearson JL, Abrams DB, Niaura RS, et al. Public support for mandated nicotine reduction in cigarettes. Am J Public Health 2013;103:562-7.

9 Pilusa ML, Mogotlane MS. Worker knowledge of occupational legislation and related health and safety benefits. Curationis 2018;41:1-6.

10 Yildiz AN, Karadag O, Gonen MO, et al. Knowledge and attitude of TAXI drivers on the new legislation for smoke-free taxis: an occupational health perspective. Pak J Med Sci 2010;26:111-6.

11 Liang Y-xin, Su Z, Wu W-ai, et al. New trends in the development of occupational exposure limits for airborne chemicals in China. Regul Toxicol Pharmacol 2003;38:112-23.

12 Liang Y, Xiang Q. Occupational health services in PR China. Toxicology 2004;198:45-54.

13 Dita M, Atmojo TB, Sari Y. The correlation between knowledge about occupational accidents and safe work behaviors among employees at the production division of Pt X Indonesia. The 1st International Conference on Health, Technology and Life Sciences, KnE Life Sciences, 2019:123-31.

14 Lin CW. The effects of policy knowledge on attitudes and behaviors towards participation in educational policy-making among parents: a structural education modeling approach. Education 2012;132:484-98.

15 Bloom AJ, Smoot DA, Shore TH, et al. Toward a perceptual model of smoking policy satisfaction. J Soc Psychol 1992;132:675-84.

$16 \mathrm{Su}$ Z. Occupational health and safety legislation and implementation in China. Int J Occup Environ Health 2003;9:302-8.

17 Su Z, Wang S, Levine SP. Occupational health hazards facing China workers and possible remedies. Beyond Transition 2002;13:37-40.

18 Gao X, Sun L. Current status of the occupational health and safety countermeasures in Beijing, China. Ind Health 2004;42:116-23.

19 China health statistic yearbook-Guangdong Province, 2012, Guangdong bureau of statistics of China.

20 Brown GD. China's factory floors: an industrial hygienist's view. Int J Occup Environ Health 2003;9:326-46.

21 Liang YX, WL Y. Rational contemplation of promoting socia responsibility and consciousness in enterprises [in Chinese]. Chin $J$ Ind Hyg Occup Dis 2007;25:631-3.

22 Wang X, Wu S, Song Q, et al. Occupational health and safety challenges in China--focusing on township-village enterprises. Arch Environ Occup Health 2011;66:3-11.

23 Agresti A. Categorical data analysis. New York: Wiley, 2002

$24 \mathrm{Hu} \mathrm{X}$, Cook S, Salazar MA. Internal migration and health in China Lancet 2008;372:1717-9.

25 Wong O. Regulation of occupational exposures in China. Reg Toxicol Pharm 2003;38:109-11.

26 Department of Population, Social Science and Technology Statistics, National Bureau of Statistics and Department of Planning and Finance, Ministry of Labour and Social Security. China Labour Statistical Yearbook [in Chinese]. Beijing: China Statistics Press, 2005.

27 Peng J. Concerns about occupational safety of migrant workers [in Chinese]. People's Daily 2004.

28 Christian MS, Bradley JC, Wallace JC, et al. Workplace safety: a meta-analysis of the roles of person and situation factors. J Appl Psychol 2009;94:1103-27.

29 Seo D-C. An explicative model of unsafe work behavior. Saf Sci 2005;43:187-211.

30 Xiao Y-ni, Huang Z-xiong, Huang S-bin, Huang ZX, Cao XO, et al. [Associations of occupational safety atmosphere and behaviors with unintentional injuries]. Zhonghua Lao Dong Wei Sheng Zhi Ye Bing Za Zhi 2012;30:488-92. 